\title{
CONCEPTUALISING AN EPISTEMICALLY DIVERSE CURRICULUM FOR A COURSE FOR ACADEMIC DEVELOPERS
}

\author{
L. Quinn* \\ e-mail: I.quinn@ru.ac.za
}

\author{
J. Vorster* \\ e-mail: j.vorster@ru.ac.za
}

${ }^{*}$ Centre for Higher Education Research, Teaching and Learning

Rhodes University

Grahamstown, South Africa

\section{ABSTRACT}

In this conceptual article we use Luckett's model for an epistemically diverse curriculum, Kitchener's levels of cognition and Maton's concepts of knowledge and knowers to analyse a curriculum of a postgraduate diploma in higher education specifically for academic developers. We describe three meta-level frameworks which we offer to our participants to make explicit the pedagogy of the course. Our main argument is that a course which prepares participants to practise in the complex contemporary higher education context requires them to engage with specific kinds of knowledge, ways of thinking and ways of being so that they can contribute towards addressing the numerous and vexing teaching and learning challenges in their institutional contexts. We argue that analyses such as these help to make explicit the organising principles of a curriculum to the curriculum designers themselves who are then able to use the insights to strengthen the design, pedagogy and assessment of their courses.

Keywords: academic development, pedagogy

\section{INTRODUCTION}

We have argued elsewhere that it is time for 'veterans' of the field of academic development (AD) to think about ways in which they can induct newcomers into the field in more systemic and systematic ways. One of the ways, we suggest, is through offering a formal qualification (Quinn and Vorster 2014). In keeping with this belief, and because we have been working in a well-established teaching and learning centre for two decades now, in 2011 we introduced a Postgraduate Diploma in Higher Education (PGDip in (HE)) for academic developers from universities across South Africa (SA). In designing the curriculum for the Diploma we drew on the work we have been doing, as academic staff developers, with lecturers both in our own institution and in a range of other SA higher education institutions. 
We are currently teaching our third cohort of academic developers. ${ }^{1}$ As this is still a relatively new course and possibly the only one of its kind both in SA and further afield, we have been very interested in researching and reflecting on the ways in which the course is contributing to the knowledge, practices and agency of academic developers who work in a myriad complex and difficult contexts in contemporary SA. The field of AD is highly diverse and needs to respond to a fast changing higher education context. Currently, for example, there are urgent calls for transformation and decolonisation of institutions and curricula in South Africa (see for example, Mbembe 2015). Academic developers could be centrally involved in developing understandings of what this means and contribute to effecting important changes in their institutions. However, AD varies across contexts; it could include various forms of student and academic staff development as well as curriculum and institutional development. Being an effective academic developer is not an easy task and we would argue requires certain kinds of knowledge, ways of thinking and ways of being (Dall'Alba and Barnacle 2007). We believe that failing to pay attention to all these aspects (or focusing just on certain aspects) in our course will not prepare academic developers to be able to design and implement academic development initiatives in ways that might contribute to solving the many, varied complex teaching and learning problems they may encounter in their specific institutional contexts.

Building on earlier research (Vorster and Quinn 2015), we use Kathy Luckett's 'model for an epistemically diverse curriculum' (Luckett 2001) ${ }^{2}$ to theorise ways in which the curriculum for our course is enacted to ensure that we pay attention to knowledge, cognition, ways of being and ways of practicing academic development. Curriculum as used in this article refers to disciplinary content as well as pedagogy and assessment. The purpose for this analysis is to enable us to make visible the principles that underpin the curriculum (Bernstein 2000) of the course both for ourselves and for the academic developers with whom we work. Making more explicit the epistemological, ontological and axiological intentions of the curriculum could help us to work together with our participants to achieve the goal of the course.

\section{POSTGRADUATE DIPLOMA IN HIGHER EDUCATION FOR ACADEMIC DEVELOPERS}

Our current cohort consists of 23 participants from 11 institutions including research intensives, comprehensives and universities of technology. ${ }^{3}$ Institutions are further differentiated in terms of historical legacies such as being historically black/white, rural/urban, well-resourced/underresourced; relatively large or small, and so on. This means that institutional contexts are differently enabling or constraining for academic development work. In addition to institutional 
diversity, the participants' backgrounds also vary in terms of their home disciplines and fields, their experience of higher education and of academic development. These contextual factors influence the design and implementation of the curriculum.

The course level is equivalent to that of an honours degree; it consists of six compulsory modules which are each taught in a week-long face-to-face teaching session across two years. The modules are: The higher education context; Teaching and learning in higher education; Curriculum development; Assessment of student learning; Development, enhancement and assurance of quality teaching and learning; and Conceptualising and designing contextually appropriate $\mathrm{AD}$ initiatives. Aside from the contact sessions, participants' learning between sessions is supported by an on-line Learning Management System. For the first five modules participants are required to submit a module assignment in which they provide evidence that they have met the outcomes of the course. In preparation for the module assignment, they are given smaller tasks as scaffolding. The module assignments, although compulsory, are not assigned a mark, however, we ensure that participants receive detailed developmental feedback on all their tasks and assignments. Towards the end of the two years participants work on revising the five assignments to write a coherent, integrated portfolio which documents their learning as academic developers and provides evidence of how they have been able to or plan to put into practice the knowledge they have gained over the two years 'to conceptualise, design and implement formal and informal academic development initiatives (with a particular focus on academic staff development) appropriate to their specific contexts' (PGDip (HE) course guide 2015-2016).

In the following section we briefly outline the analytical tools we used along with Luckett's model for an epistemically diverse curriculum to assist us to conceptualise the curriculum for the Diploma.

\section{ANALYTICAL TOOLS}

\section{Four domains of knowledge}

After offering the course for the first time we decided, in order to make visible the structuring principles of the course, to analyse the nature of the knowledge in the curriculum (Vorster and Quinn 2015). In the first phase of the project we identified and named the different domains of knowledge introduced in the course and in the second phase we analysed what and how knowledge was recontextualised to design the curriculum, and how it might enable cumulative learning and knowledge building. We argued that because the field of AD is so varied, complex 
and context dependent we must ensure that in our course we provide opportunities for academic developers to build cumulative knowledge, that is, knowledge that is coherent, that lays a solid foundation for further knowledge-building and that can be applied in innovative ways in the range of institutional contexts in which they work.

From our analysis of our course documentation we identified four different domains of knowledge that academic developers require to respond appropriately to the complex teaching and learning needs in their contexts:

1. Analytical framework (K1): Drawing on the work of Margaret Archer (1995), we introduce the participants to social realist concepts of structure, culture and agency to use as a meta-level analytical framework for analysing their specific contexts in order to make strategic decisions about their practice.

2. Knowledge of the field of $A D(K 2)$ : To make decisions about how to practice $\mathrm{AD}$ in specific contexts, it is useful to explore the historical trajectory of AD internationally, nationally and institutionally in order to learn from past successes and failures and to share 'good' practices across the sector. We also focus on issues of academic developers' identity formation and the identity shifts that can occur as they gain more knowledge of the field and experience of AD work.

3. Knowledge of the higher education context (K3): In the course we build knowledge of the HE context at macro, meso and micro levels. At the macro level we examine the changing role of $\mathrm{HE}$ as an institution in society both internationally and in South Africa. At meso and micro levels we encourage participants to explore their institutional contexts in detail in order to better understand how AD can contribute to developing academics as teachers and improving student learning.

4. Substantive knowledge related to teaching and learning (K4): Throughout the course we draw on research and theories from the broader field of higher education studies (HES) to build academic developers' substantive knowledge of teaching and learning to enable them to design initiatives that will impact positively on key aspects of the academic project such as the development of academics as teachers, epistemological access for students, curriculum design, assessment of and for student learning and quality assurance and enhancement. We argue that when and how to use this domain of knowledge depends on how well an academic developer understands the first three knowledge domains.

Although in one module there may be a focus on a particular domain of knowledge, our analysis 
showed that all domains of knowledge are present to a lesser or greater extent in each of the modules, thus making it possible for participants to see the interrelatedness of the concepts and theories across the domains and the various ways in which academic development is, or needs to be, practiced in their contexts.

\section{Knowers}

In curriculum design processes it is important to focus on knowledge but as pointed out by Maton (2013), all practices, beliefs, and knowledge claims are about something and are enacted by someone; there is thus always 'knowledge' and there are always 'knowers'. The former is about what counts as legitimate knowledge in a field and the latter about who can claim to produce and/or have legitimate knowledge. Applying this to our context, we argue that induction for our participants into the field of $\mathrm{AD}$ should consider both knowledge and knowers; we should offer opportunities for participants to engage with both the powerful knowledge of the field, and to explore identities and dispositions for academic developers (Vorster and Quinn 2015).

In keeping with our belief that learning does not just happen in the heads of individuals but involves all aspects of their being, we are interested in how 'knowledge and skills are to be integrated into skillful practice or, more broadly, contribute to the transformation of the learner' (Dall'Alba and Barnacle 2007, 680). In our analysis of the curriculum we pay particular attention to ways in which different kinds of knowledge and the pedagogy of the course contribute to shaping academic developer identities that emerge during the course.

\section{Cognition}

In our analysis, in addition to using analytical lenses related to knowledge and knowers described above, we also explore cognition, that is, the mental actions or processes of acquiring knowledge. Like Luckett, we draw on Kitchener's (1983) seminal work on three levels of cognition:

1. First-level cognition: at this level individuals engage in cognitive tasks such as memorising, reading, computing, etc. while learning.

2. Meta-cognition: at this level individuals monitor their own progress/thinking while engaging in the first level tasks. It is about individuals having active control over their cognitive processes while engaged in learning.

3. Epistemic cognition: at this level individuals reflect on the limits of knowing, the certainty 
of knowing and the criteria for knowing. This level of cognition influences how individuals understand the nature of challenges they confront in their practices and how they then draw on the knowledge they have gained to decide which strategies/actions will best serve to solve the problem or deal with difficult challenges they confront.

In order for cumulative knowledge-building, as alluded to earlier, to take place we believe that there needs to be planned space in the curriculum for participants to engage with specific domains of knowledge using, at different points in time, all three levels of cognition as proposed by Kitchener.

\section{LUCKETT'S MODEL OF AN EPISTEMICALLY DIVERSE CURRICULUM}

Using an adapted version of Luckett's (2001) model of an epistemically diverse curriculum as a 'thinking tool' (31), in conjunction with the other 'lenses' described above, in this section we provide an analysis of the curriculum of the PGDip which demonstrates ways in which we believe the course makes possible epistemological, cognitive and ontological access for academic developers. Figure 1 illustrates four ways of knowing which Luckett proposes should be present in any HE curriculum. She suggests that the emphasis and combinations of each of the four ways of knowing would be different, depending on the nature of the qualification and context of implementation. In addition, it is important to understand that the model does not imply that the knowledge in each of the quadrants necessarily has to be introduced to students in a linear way.

In the section below we briefly describe the quadrants in Figure 1 and how each quadrant applies to our course. Thereafter we conceptualise in a more holistic way in which the quadrants work together to form an integrated curriculum.

Quadrant 1: The kind of teaching and learning that takes place in this quadrant is the learning of propositional knowledge, that is, what is traditionally associated with university teaching and learning. It is about students gaining foundational competence. In order for students to undertake this kind of learning they are usually required to engage in first-level cognitive activities such as reading, making notes, listening to lectures, and computing.

In each of the modules of our course, participants engage with propositional knowledge related to the field of higher education studies (HES) and the practice of AD. This is particularly the case in the modules that foreground substantive knowledge related to teaching and learning, curriculum development, assessment for and of student learning and the evaluation of teaching and courses (K4). Many of the participants who do this course have had very little exposure to 
this propositional knowledge. This is partly due to the fact that historically there has been no formal induction into the field but it is also due to the nature of the field. In many HE contexts teaching and learning are understood to be commonsense activities that do not require any theoretical underpinnings (Light and Cox 2000; Clegg 2009). In such contexts AD is practiced as if it were an a-theoretical field and practitioners employ only 'craft knowledge' which does not offer strong foundations for facing the challenges of contemporary HE (Scott, Yeld and Henry 2007). Along with Scott et al. we believe academic developers need foundational knowledge to enable them to adopt scholarly approaches to their work. However, exactly what counts as 'disciplinary' knowledge of the field of $\mathrm{AD}$ is unclear and contested because knowledge is drawn from a range of other fields and disciplines such as sociology, psychology, political studies, and linguistics. It has been argued that we need to strengthen the 'stockpot' of theories from which we draw in this field (Shay 2012; Boughey 2013). So, part of our interest in offering this course is to both examine existing frameworks and to contribute to building stronger epistemic frameworks for our field. We are cognisant of the need to encourage our participants to engage with content/knowledge that draws not only on scholars from the global North but also from the global South. In so doing we attempt, in our course, to explore what it means to be academic developers in African institutions.

Traditionally, in higher education much of this propositional knowledge has been offered to students in the form of formal lectures in which knowledge is transmitted to students. In our course, our teaching is informed by socio-cultural principles of learning, so much of our teaching involves our participants engaging with texts, with one another and with the facilitators in order for them to build their understandings of the knowledge introduced to them.

In relation to this quadrant then, much of the teaching involves explicitly inducting students into the literacy of the discipline to enable them to express themselves in writing and meet the assessment requirements of the course. In part, this writing requires them to use the academic literacy conventions of the humanities/education. In addition, for most of our participants English is an additional language, they come from a range of disciplinary backgrounds, and many of them have not been explicitly taught these disciplinary ways of writing.

\section{subjective/contextual}

3

experiential knowledge (personal competence)
4

epistemic knowledge

(reflexive competence) 
Learning by engaging personally, thinking reflexive developing meta-cognition,

thinking epistemically, contextually and systemically

\author{
practice \\ practical knowledge \\ (practical competence) \\ knowing how, application of \\ disciplinary knowledge \\ learning by doing apprenticeship
}

2 theory

$$
\begin{aligned}
& \text { propositional knowledge } \\
& \text { (foundational competence) } \\
& \text { knowing that, appropriating } \\
& \text { disciplinary knowledge } \\
& \text { traditional cognitive learning }
\end{aligned}
$$

1

\section{objective/reductionist}

Figure 1: Model of an Epistemically Diverse Curriculum (Luckett 2001, 31)

Although it is necessary in our course to ensure that there is a strong focus on propositional knowledge, we do not believe that on its own it will prepare participants for professional practice in their institutional contexts. We thus concur with Luckett that '... this way of knowing needs to be challenged and complemented by other ways of knowing' (Luckett 2001, 32).

Quadrant 2: In this quadrant teaching and learning are about introducing students to practical knowledge; to knowledge which helps them to apply disciplinary knowledge they have acquired in quadrant 1. It is learning that happens under the guidance of the teacher and takes place in laboratories, classrooms, field trips, etc. It is an opportunity for students to gain practical competence by applying their knowledge in relatively controlled, safe circumstances.

In this quadrant, our participants are required to begin to ask themselves: What do the theories and concepts mean to me in the context of my work as an academic developer in my specific institution? Requiring them to do this encourages them to begin to engage at a more meta-cognitive level where they consider their current conceptualisation of $\mathrm{AD}$ and their practice in the light of the ideas they have been introduced to in the course. To understand why things are the way they are, they need to engage actively with knowledge of the macro higher education context (K3) to see how broader economic, social and political changes globally and nationally have impacted on their institutions. They need to be familiar with the historical trajectory of $\mathrm{AD}$ (K2) both internationally and nationally, and in their institutions. Having worked with these ideas, participants are then in a position to begin to apply some of the 
substantive knowledge of aspects of teaching and learning (K4) to critique current institutional practices. Participants are afforded the opportunity, in the safe space of the classroom, to apply semantically dense concepts learned in quadrant 1 in order to begin to articulate how they imagine they, as academic developers, could in practical ways respond to teaching and learning challenges in their institutions. Assessment at this stage is all formative and students are given constructive feedback from peers and facilitators on their attempts to build practical knowledge which they will hopefully be able to implement in their contexts of practice.

Quadrant 3: In this quadrant learning takes place in contexts away from the classroom/laboratory, etc. Students are given opportunities to gain experiential knowledge in real-world contexts. In vocational and professional courses this is often done through various work-integrated learning programmes. In this quadrant students learn by engaging personally and thinking reflexively and meta-cognitively. Much of the learning in this quadrant is about gaining personal competence; learning about themselves and their own thinking processes.

In our course, this is learning that happens when our participants go back to their institutions and they begin to apply the learning from quadrants 1 and 2 to novel and often messy situations that they confront in their daily practice as academic developers. In this quadrant we are hoping that participants begin to engage in critical reflection in and on their practice (Schön 1983) and begin asking themselves, in addition to the question above, other questions such as: How did I respond to that challenge? Why did I act in the way I did? Could I have done things differently? How was or wasn't I able to apply my learning from the PGDip to my practice? And so on.

This kind of critical reflection happens when participants recognise, for example, through engagement with the theory and through learning from their colleagues in the class, that there might be more productive ways of approaching various aspects of $\mathrm{AD}$ in their contexts. However, since there is no direct relationship between the theories and concepts participants are exposed to on the course and the 'problems' they encounter in their work contexts, they need to use their professional judgments to decide about the most appropriate courses of action given their contextual constraints and enablements (see for example Barnett 2006 in Shay 2015). As with all professional programmes, the aim with this PGDip (HE) is that participants will be able to practice in ways that are theoretically informed.

In this quadrant the knowledge domains of K2, K3 and K4 are integrated. Participants are encouraged in assignments and summative assessment portfolios to reflect critically on their workplace actions using the theoretical and practical knowledge they have gained in quadrants 1 and 2. The intention in this quadrant is for students to gain personal competence through 
'becoming aware of their own learning processes and to undertake 'double-loop learning' or self-reflexive thinking' (Luckett 2001, 33).

In each of the module assignments students are required to provide evidence of foundational, practical and personal competence. In order to help them do this in writing our pedagogy throughout the course includes an explicit focus on teaching them how to demonstrate criticality, reflectivity and praxis. Following Stierer (2008), we believe these are key features of the written assessment of courses such as ours. It is beyond the scope of this article to discuss this in detail. (See Quinn and Vorster (2015) for an in-depth exploration of the pedagogy for fostering these elements in a course for lecturers. We employ very similar pedagogic practices in the course for academic developers).

Quadrant 4: In this quadrant students are further encouraged to develop Kitchener's second and third levels of cognition: 'meta-cognition', defined by Luckett as 'an awareness of how and why one thinks as one does' and 'epistemic cognition' defined as 'the capacity to think epistemically, to recognise and evaluate the assumptions and limits of theories of knowledge, and to be able to suggest alternatives' (Luckett 2001, 33). In summary, students are given opportunities to develop meta-cognition, to think epistemically, contextually and systematically. Operating in this quadrant requires high levels of reflexive competence; the ability to understand that there are diverse ways of knowing and a willingness on the part of students to 'rethink their assumptions about values, ethics, and social responsibility' (ibid).

It is through the introduction of the social realist analytical framework (K1) in the course that we provide opportunities for our participants to develop meta-cognition and learn to think 'epistemically, contextually and systematically' (ibid, 31) in order to contribute in a meaningful way to improving teaching and learning in their institutions.

By introducing our participants to the basic ideas of Roy Bhaskar's critical realist philosophy (1979) we offer them the analytical tools to go beyond making only superficial observations of $\mathrm{AD}$ (and their own roles in their institutions) to uncovering and understanding the underlying mechanisms which make the observable possible. Using Archer's (1995) social realist concept of culture could contribute to knowledge about how the ideas, beliefs, values, ideologies and theories about higher education broadly and about academic development specifically have or haven't contributed enabling conditions for their practice. Archer's concept of structure is intended to help participants uncover how relevant structures at the international, national and institutional levels have shaped the practice of academic development. Archer's concept of agency is intended to help participants gain insights into how the relevant people and the positions they hold in institutions as well as their sense of their own knowledge and 
capabilities have impacted on academic development practices. Examining the interaction between these three aspects of the social world could generate critical insights which would contribute to informing planning and decision-making in relation to academic development practices in their contexts.

Questions participants could/should be asking themselves in this quadrant: In what ways did or didn't the theoretical concepts and ideas that underpinned my thinking and my actions enable me to understand the generative mechanism that account for why things are the way they are? Do I need to seek out new/different ideas to inform my practice? Whose interests are served by the theories used or by the way things are in my context? If unfair or poor practice is identified, what can I do to transform the way things are and the way things are done in my institution? In what way can I as academic developer contribute to transforming this institution so that the majority of students feel recognised and have a chance at success? Participants are, therefore, encouraged to be critical of the propositional, practical and experiential knowledge they have gained in the course and to 'understand knowledge as socially constructed, historically and culturally specific, and that their own judgments are contextually contingent' (Luckett 2001, 32).

\section{INTEGRATION OF THE FOUR QUADRANTS}

In a course such as ours, which prepares people for professional practice, we would argue that integration of the knowledges and competencies of the four quadrants described above is essential. In each module the pedagogy and the assessment of the course encourages participants to operate in all four quadrants simultaneously although with different emphases and different levels of epistemic and cognitive complexity as the course proceeds. The ultimate goal of the course is for participants to operate in quadrant 4 , however, in order for them to do this, they need all four kinds of knowledge described in Luckett's model as they engage in the four domains of knowledge identified above; in each of the modules they also operate across all three of Kitchener's levels of cognition. How this could be achieved is explained below.

Before the start of each module, participants are required to do a pre-module task in which they respond to questions in which they reflect on the relationship between the topic of the module and their experiences with that particular aspect of academic development practice in their context. For example, in the curriculum module, participants are asked to respond to questions such as:

- What role do you think curriculum plays within higher education? 
- What ideas in relation to curriculum transformation are evident in your institution?

- What are the dominant ideas that shape academics' curriculum development practices in your institution?

- What institutional structures (committees, policies) exist to guide curriculum development?

- What role do you play within your institution in relation to curriculum development?

Through these questions participants reflect on curriculum both in relation to the higher education context as well as their institutional contexts using the social realist lenses of culture, structure and agency. In addition, they reflect on their own experiences as academic developers in relation to curriculum development. Therefore, this exercise requires them to work with the organising framework and to reflect on their experiences. In terms of epistemic diversity, the exercise engages participants in both experiential and epistemic knowledge. In the course participants are introduced to propositional knowledge about curriculum. The propositional knowledge is critiqued and various theories are brought in relation to each other. They are also provided with multiple opportunities to reflect on how the propositional knowledge relates to practices in their institution and what the knowledge they gain, means for their roles as academic developers. This moves them into the practical knowledge quadrant of Luckett's model. For the presentation task at the end of the module, participants examine aspects of curriculum development in their context that they, as academic developers, can influence given what they have learned in the module. In this module, therefore, as in all six of the modules, participants work with the four domains of knowledge (K1, K2, K3 and K4) and engage in criticality, reflectivity and praxis; they use and practice all four kinds of knowledge in Luckett's model, i.e., propositional, practical, experiential and epistemic. For the module assignment, participants are required to use the propositional knowledge acquired through the module, and their analysis of their institutional contexts to conceptualise the role of academic development and their role in relation to the design and transformation of curricula (at all levels) appropriate for their institutional type and for a university in Africa.

\section{MAKING VISIBLE THE INVISIBLE}

As mentioned in the introduction, our reason for researching the knowledge of the course (Vorster and Quinn 2015) and conceptualising the curriculum in this article, was to make visible to ourselves, as course designers and facilitators, the structuring principles which underpin our selection of knowledge and other curriculum decisions. The ultimate purpose of both these 
studies was to enable us to make visible the invisible, not just to ourselves but also to our course participants. Bernstein (2000) argues that adopting a visible pedagogy is an appropriate strategy to enable students to make sense of what is required of them. Making visible the pedagogy of a course means that teachers make explicit to students the what and why of the curriculum and how they are required to represent their learning in assessment tasks. It means signaling to them the epistemic expectations of the course (Shalem and Slonimsky 2010).

In the first module we introduce participants to three frameworks that we hope will enable them to develop both metacognition and epistemic cognition. The first framework is based on Stierer's conceptualisation (2008) of how learning happens in formal programmes aimed at preparing academics for their teaching role. As noted above, Stierer argues that participants on these kinds of courses need to develop and demonstrate criticality, reflectivity and praxis. In the course we examine what each of these ways of learning and practicing means in terms of our expectations in relation to the pedagogic principles that underpin the course. Participants are shown examples of what criticality, reflectivity and praxis might look like in the writing and learning that they do for the course. Another aspect of making visible the course principles is that we introduce them to the second framework, which is the four domains of knowledge that the course aims to develop. Even though the four domains of knowledge are separated analytically, they are integrated in both the pedagogy of the course and the practice of academic developers. Finally, they are introduced to the third framework, the social and critical realist ideas related to structure, culture and agency, as a lens through which to analyse contextual enablements and constraints in relation to $\mathrm{AD}$ in their institutions and their own practice as academic developers.

Used together, these three frameworks constitute a meta-level set of lenses which participants can use to structure and explain their knowledge, practices and experiences in a coherent way. In addition, they enable participants to explore their identities and dispositions as knowers - both as scholars and as practicing academic developers.

\section{CONCLUSION}

In this article we have conceptualised an epistemically diverse curriculum for a formal course for academic developers. We used Luckett's model as well as a few additional analytical tools to demonstrate how the course is designed to meet its purposes. Central to our conceptualisation is the belief that our curriculum must promote ways of 'knowing, acting and being' (Dall'Alba and Barnacle 2007, 679) that are appropriate in specific personal, social, historical, cultural and institutional contexts. 
As in any educational context, much depends on how a conceptualised curriculum is put into practice. The outcomes of the enacted curriculum depend on multiple variables such as the nature of the participants, the contexts they come from, and the knowledge and expertise of the facilitators.

However, we hope that through making visible the underlying organising principles of the course, the pedagogy and the assessment to ourselves, and using the three frameworks described above in our pedagogy to make visible the invisible to our participants, we will increase the likelihood of most of our participants achieving the purpose and outcomes of the course.

\section{NOTES}

1 This was the case at the time of writing the article. We are now teaching the fourth cohort of PGDip (HE) for academic developers.

2 Luckett's model was proposed as a 'thinking tool' for designing appropriate undergraduate curricula in the context of post-apartheid South Africa. We have used this heuristic extensively in our curriculum courses with lecturers and found it useful for conceptualising and analysing curricula at all levels of academia.

3 Research-intensive universities offer traditional degree programmes; universities of technology offer mostly vocationally oriented diploma programmes and comprehensive universities offer a combination of both types of programmes.

\section{REFERENCES}

Archer, M. S. 1995. Realist social theory: The morphogenetic approach. Cambridge: Cambridge University Press.

Barnett, M. 2006. Vocational knowledge and vocational pedagogy. In Knowledge, curriculum and qualifications for South African further education, ed. M. Young and J. Gamble 143-157. Pretoria: Human Sciences Research Council Press.

Bernstein, B. 2000. Pedagogy, symbolic control, identity: Theory, research, critique. Critical perspectives series (Revised edition). Lanham, Md: Rowman and Littlefield Publishers.

Bhaskar, R. 1979. The possibility of naturalism. A philosophical critique of the contemporary human sciences. Brighton, Sussex: Harvester.

Boughey, C. 2013. What are we thinking of? A critical overview of approaches to developing academic literacy in South African higher education. Journal for Language Teaching 46(2): 25-42.

Clegg, S. 2009. Forms of knowing and academic development practice. Studies in Higher Education 34(4): 403-416.

Dall'Alba, G. and R. Barnacle. 2007. An ontological turn for higher education. Studies in Higher Education 32(6): 679-691.

Kitchener, K. S. 1983. Cognition, metacognition and epistemic cognition. Human Development 26(4): 222-232.

Light, G. and R. Cox. 2000. Learning and teaching in higher education: The reflective professional. London: Sage.

Luckett, K. 2001. Responding to equity and development imperatives: Conceptualizing a structurally and epistemically diverse undergraduate curriculum in post-apartheid South Africa. Equity and Excellence in Education 34(3): 26-35. 
Maton, K. 2013. Knowledge and knowers: Towards a realist sociology of education. London, UK: Routledge.

Mbembe, A. 2015. Decolonizing knowledge and the question of the archive. https://africaisacountry. atavist.com/decolonizing-knowledge-and-the-question-of-the-archive (accessed 6 December 2015).

PGDip (HE) Course Guide. 2015-2016. CHERTL, Rhodes University: Grahamstown.

Quinn, L. and J. Vorster. 2014. Isn't it time to start thinking about 'developing' academic developers in a more systematic way? International Journal for Academic Development 19(3): 255-258.

Quinn, L. and J. Vorster. 2015. Pedagogy for fostering criticality, reflectivity and praxis in a course for lecturers on teaching. Assessment and Evaluation in Higher Education. DOI:10.1080/02602938.2015.1066756.

Scott, I., N. Yeld and J. Hendry. 2007. The case for improving teaching and learning in South African higher education. Higher Education Monitor 6. Pretoria: Council on Higher Education.

Schön, D. 1983. The reflective practitioner: How professionals think in action. London: Temple Smith.

Shalem, Y. and L. Slonimsky. 2010. Seeing epistemic order: Construction and transmission of evaluative criteria. British Journal of Sociology of Education 31(6): 755-778.

Shay, S. 2012. Educational development as a field: Are we there yet? Higher Education Research and Development 31(3): 311-323.

Shay, S. 2015. Curricula at the boundaries. Higher Education. DOI 10.1007/s10734-015-9917-3.

Stierer, B. 2008. Learning to write about teaching: Understanding the writing demands of lecturer development programmes in higher education. In The Scholarship of teaching and learning in Higher Education, ed. R. Murray, 34-45. Maidenhead: Open University Press.

Vorster, J. and L. Quinn. 2015. Towards shaping the field: theorising the knowledge in a formal course for academic developers. Higher Education Research and Development 34(5): 1031-1044. DOI:10.1080/07294360.2015.1070126. 